\title{
Attachment, Infidelity, and Loneliness in College Students Involved in a Romantic Relationship: The Role of Relationship Satisfaction, Morbidity, and Prayer for Partner
}

\author{
M. Graça Pereira • Ebru Taysi • Fatih Orcan • Frank Fincham
}

Published online: 27 September 2013

(C) Springer Science+Business Media New York 2013

\begin{abstract}
This study examined the mediating effects of relationship satisfaction, prayer for a partner, and morbidity in the relationship between attachment and loneliness, infidelity and loneliness, and psychological morbidity and loneliness, in college students involved in a romantic relationship. Participants were students in an introductory course on family development. This study examined only students $(n=345)$ who were involved in a romantic relationship. The average age of participants was $19.46(\mathrm{SD}=1.92)$ and $25 \%$ were males. Short-form UCLA Loneliness Scale (ULS-8), (Hays and DiMatteo in J Pers Assess 51:69-81, doi:10.1207/s15327752jpa5101_6, 1987); Relationship Satisfaction Scale (Funk and Rogge in J Fam Psychol 21:572-583, doi:10.1037/0893-3200.21.4.572, 2007); Rotterdam Symptom Checklist (De Haes et al. in Measuring the quality of life of cancer patients with the Rotterdam Symptom Checklist (RSCL): a manual, Northern Centre for Healthcare Research, Groningen, 1996); Prayer for Partner Scale, (Fincham et al. in J Pers Soc Psychol 99:649-659, doi:10.1037/a0019628, 2010); Infidelity Scale, (Drigotas et al. in J Pers Soc Psychol 77:509-524, doi:10.1037/0022-3514.77.3.509, 1999); and the Experiences in Close Relationship Scale-short form (Wei et al. in J Couns Psychol 52(4):602-614, doi:10.1037/0022-0167.52.4.602, 2005). Results showed that relationship satisfaction mediated the relationship between avoidance attachment and loneliness and between infidelity and loneliness. Physical morbidity mediated the relationship between anxious attachment and psychological morbidity. Psychological morbidity mediated the relationship between anxious attachment and physical morbidity. The present results expand the literature on attachment by presenting evidence that anxious and avoidant
\end{abstract}

M. G. Pereira (凹)

School of Psychology, University of Minho, Braga, Portugal

e-mail: gracep@psi.uminho.pt

E. Taysi

Suleyman Demirel University, Isparta, Turkey

F. Orcan · F. Fincham

Florida State University, Tallahassee, FL, USA 
partners experience loneliness differently. Implications for couple's therapy are addressed. Future research should replicate these results with older samples and married couples.

Keywords Attachment - Infidelity - Loneliness - Relationship satisfaction · Prayer for partner $\cdot$ Morbidity $\cdot$ Romantic relationships

\section{Introduction}

Loneliness or an absence of intimacy and support in social interactions (de Jong Gierveld et al. 2009) occurs widely despite the common human need to belong (Rotenberg 1994). Loneliness may occur as a result of the type of affectional bond or attachment typically formed by a person, specifically, insecure attachment styles contribute to the development of psychological distress, such as loneliness (Hazan and Shaver 1987). In romantic relationships, loneliness may also be experienced when the relationship with the partner has been damaged because of infidelity.

\section{Adult Attachment and Loneliness}

Weiss (1973) proposed attachment theory as a framework that could be used to combine findings about loneliness and romantic relationships. In attachment theory, Bowlby (1973, 1980) described the quality of affectional bonds, that develop between children and their primary caregivers, emphasizing these early relationships with caretakers, as a great influence on adult romantic relationships (Hazan and Shaver 1987). Some researchers (Griffin and Bartholomew 1994; Simpson and Rholes 1997) suggested a two dimensions model for attachment in adults: avoidance and anxiety. Avoidant people investless in their relationships and try to be psychologically and emotionally independent. Anxiously attached people fear being rejected and abandoned (Hazan and Shaver 1987).

By highlighting the relationship between loneliness and attachment, Weiss (1973) described emotional and social loneliness. The first, is the deficit of intimate attachment relationships and the second, the absence of a social network. Research has shown a strong relationship between attachment styles and loneliness (DiTommaso et al. 2003; DiTommaso and Spinner 1997; Hazan and Shaver 1987; Kobak and Sceery 1988; Larose and Bernier 2001; Man and Hamid 1998). Secure individuals report little loneliness and the opposite is true for insecure individuals. Therefore, partners with an avoidant attachment style are more independent psychologically and emotionally, and minimize the importance of close relationships and, as a result, may feel lonely due to the deficit in closeness. Those with an anxiety attachment style fear being rejected and abandoned. They also want others to be with them and available, all the time. As a result, they may develop a negative evaluation that leads them to feel lonely.

In addition to the direct relationship between attachment and loneliness, research has found several mediators that link attachment to loneliness including social self-efficacy and self-disclosure (Wei et al. 2005a), social skills (DiTommaso et al. 2003), and social support (Bernardon et al. 2011). However, few studies have examined the indirect link between attachment and loneliness, in romantic relationships (e.g., Bernardon et al. 2011).

In romantic relationships, relationship satisfaction indicates the affect experienced in a relationship and is influenced by the extent to which a partner fulfills the other's most important needs (Rusbult et al. 1998). Among dating partners, loneliness may result from dissatisfaction with the romantic relationship. Several studies showed a negative 
correlation between loneliness and the quality of romantic relationships (Fitzpatrick et al. 2003; Flora and Segrin 2000; Segrin et al. 2003; Yum 2003). Thus, loneliness may not simply reflect a deficit in personal individual functioning but result from feelings of dissatisfaction within a current relationship (de Jong Gierveld et al. 2009).

Hazan and Shaver (1987) believe that attachment styles have a crucial effect on relationships and on the quality of romantic relationships. A secure adult attachment offers love, care and support, sustaining satisfactory relationships (Cann et al. 2008). The connection between attachment and satisfaction, in a relationship, is well documented. Securely attached individuals reported significantly greater relationship satisfaction and individuals with avoidant or anxious attachment styles show lower levels of satisfaction and intimacy (Feeney and Noller 1990; Hazan and Shaver 1987; Keelan et al. 1998) suggesting that dissatisfaction with a relationship increases feelings of loneliness.

Prayer, Relationship Satisfaction, and Loneliness

Because loneliness can be stressful, individuals may turn to prayer to cope. Prayer has been described in terms of "proximity" (Kirkpatrick 1999), in which an individual may compensate for a lack of closeness in a relationship with closeness to God. Kirkpatrick (1992) applied attachment theory to spirituality/religion and proposed two hypotheses to explain the relationship between early parent-child attachment and one's attachment to God. The first hypothesis has to do with correspondence theory and suggests a link between individual attachment and spiritual/religious behavior. Therefore, God may be seen as an attachment figure and as a "safe haven" in the face of a fear or threat, and a "secure base" from which to explore the world (Kirkpatrick 1992, 1995, 1999). In fact, Kirkpatrick and Shaver $(1990,1992)$ claimed that prayer offered a safe haven in times of distress. Avoidant partners are more likely to describe themselves as agnostic and, on the other hand, anxious/ ambivalent adults are more likely to exhibit religious behaviors (Kirkpatrick and Shaver 1990). Research also shows that secure adults see God as more loving, less controlling, and more available than avoidant adults (Kirkpatrick 1998). The second hypothesis is based on compensation theory (Kirkpatrick 1992) and suggests that individuals who develop insecure attachment styles, from their earlier relationships, may form secure attachment bonds with God, as an alternative attachment figure (Kirkpatrick 1992). Research that supports this theory shows that insecure individuals try to get closer to God over time (Granqvist 1998; Kirkpatrick and Shaver 1990). Prayer may be perceived as a spiritual activity that might, therefore, affect romantic relationships.

Recent research has shown that praying for one's partner increases relationship satisfaction (Fincham et al. 2008). In fact, praying for the partner may also be helpful when partners have an anxious attachment style. Anxious attached partners perceived more conflict in their romantic relationships (Campbell et al. 2005), and prayer for a partner may help in conflict resolution (Butler et al. 2002; Lambert and Dollahite 2006).

Anxious partners may pray more for their partners than avoidant attached partners since they are more likely to feel a fear of abandonment (Kirkpatrick and Davis 1994; Kirkpatrick and Hazan 1994) and, as a result, insist on maintaining an even dissatisfied bond (e.g. Mikulincer and Shaver 2007). On the other hand, praying for the partner may also be related to less feelings of loneliness, in anxious partners, since prayer restores one's sense of belonging (Levine 2008; Kirkpatrick 1992). Conversely, a deficit in closeness (Weiss 1973), in avoidant partners, may not meet the basic needs for attachment and their partners may still feel less satisfied in their relationships and, as a result, pray less and feel lonely. 
Attachment and Infidelity

When romantic relationships deteriorate, they become a source of stress and partners may feel an emptiness in their relationships. Infidelity may be an attempt to find a new way to relieve this stress. Because attachment is a core element that affects individuals' relational behaviors, feelings, and beliefs (Hazan and Shaver 1987; Simpson 1990), it may help explain why some people are unfaithful to their partners. Research on insecure attachment has shown that anxious individuals want long term and constant relationships (Davis et al. 2004; Feeney 2002) and fear being abandoned by their partners (Collins and Read 1990). Owing to their strong demands on a partner and needing to be loved, anxious people are unlikely to engage in an affair. On the contrary, avoidant people report fear of intimacy and less interdependence (Hazan and Shaver 1987) and, therefore, may be more prone to have an affair.

However, infidelity is also described as a means to satisfy intimacy and autonomy needs (Brown 1991). Intimacy needs emotional closeness (Glass and Wright 1997) and autonomy needs for independence (Allen and Baucom 2006). A few studies illustrate the relationship between attachment and infidelity. Allen and Baucom (2004) reported that avoidant attached men and women were more likely to engage in infidelity. Bogaert and Sadava (2002) indicated that women with an anxious attachment were more likely to engage in infidelity. In the light of these results, it is expected that avoidant partners would engage in extradyadic behaviors more than anxious partners due to their autonomy needs and fear of intimancy. However, anxious individuals may also be unfaithful if they feel their emotional needs are not fulfilled by their partners. Infidelity can be described as a transgression of the relationship's norms (Drigotas et al. 1999). Adults involved in an extradyadic relationship also display similar symptoms of depression and acute anxiety when they realize that their relationship is going to end (Allen et al. 2005). Furthermore, the unfaithful partner may feel guilt, hurt, and loneliness after experiencing infidelity (Snyder et al. 2008; Spanier and Margolis 1983). Following infidelity, psychological distress among unfaithful partners may occur (e.g., Baumeister 1998) as well as more vulnerability to psychological distress (Baumeister et al. 1995). Only one study found infidelity, not related to distress, in dating couples (Hall and Fincham 2009). Although infidelity is considered more tolerable among dating couples (Sheppard et al. 1995), more similarities than differences have been found, in behavior between dating and marital infidelity (Roscoe et al. 1988).

Several studies show that relationship dissatisfaction is related to infidelity (Allen and Baucom 2006; Atkins et al. 2001; Glass and Wright 1997; Hall and Fincham 2009). A negative relationship between marital satisfaction and infidelity has been shown for all types of infidelity: sexual, emotional or both (Glass and Wright 1997; Wiggins and Lederer 1984). Adults involved in dating infidelity are less likely to feel satisfied with their primary relationships (Atkins et al. 2001; Barta and Kiene 2005). Spiritual behaviors, like prayer for partner, may lead couples to be more benevolent, sensitive to each other's needs, respectful and more loving towards each other (Dudley and Kosinski 1990). Prayer could be affected by different psychological processes such as motivational processes, especially goals. Fincham and Beach (1999) described motivational processes as a very important process for couples when they are trying to minimize negative relationship transactions. The authors theorize that when partners experience hurtful interactions, they generally deviate from cooperative goals and adopt emergent goals which are adversarial. As a result, partners end up dealing with conflict involving negative behaviors. Praying for the romantic partner, in these situations, may serve as a time out allowing cooperative goals to become more salient, (Fincham et al. 2008) which may also facilitate partner's 
psychological well-being (Byrd et al. 2007; Maltby et al. 1999). Infidelity is an event that leads partners away from cooperative goals increasing the possibility of negative emotions, like loneliness, in the absence of prayer. Recent research showed that prayer for a partner reduces infidelity (Fincham et al. 2010) and increases trust in the relationship (Lambert et al. 2012). Therefore, after experiencing infidelity, anxious partners should be more likely to engage in prayer after feelings of dissatisfaction to comfort themselves regarding the possibility of regaining their partners' attention, love, and availability.

Adult Attachment and Physical/Psychological Morbidity

Longitudinal studies show a link between attachment style and physical health. Insecure attached individuals, in infancy, were more likely to report inflammation based illness and more non-specific symptoms when adults (Puig et al. 2012). Several authors also report an association between attachment and physical symptoms (Wearden et al. 2005). Ciechanowski et al. (2002) found that insecure attachment was related to more physical symptoms. Feeney (2000) proposed that attachment styles affect physical health through the influence of one's ability to regulate negative emotions suggesting that insecure attachment styles are linked to higher cortisol levels and increased vagal tone. Furthermore, Maunder and Hunter (2008) proposed that attachment insecurity contributes to disease risk through physiological links that mediate the relationship between stress and the immune system.

In terms of psychological morbidity, individuals with avoidant and anxious attachment styles are likely to suppress emotional responses, to show relational distress, feelings of unworthiness, excessive worry (Bogdan-Raque et al. 2011), and depressive symptoms (Besser and Priel 2003; Wei et al. 2003). Generally, the positive associations with depressive symptoms are stronger for anxious attachment than avoindant attachment, although direct effects for both types of insecure attachment have been reported (Mallinckrodt and Wei 2005; Wei et al. 2003, 2004). Anxiety and depressive symptoms have also been reported in association with insecure attachments (Lee and Hankin 2009; Lopez et al. 2001; Wei et al. 2003, 2004), negative affect (e.g., Simpson 1990), general distress symptoms (Lopez et al. 2002) and increased feelings of loneliness (Hecht and Baum 1984; Kobak and Sceery 1988; Shaaver and Hazan 1989).

At a clinical level, identification of variables that mediate the association between attachment and loneliness, infidelity and loneliness, and morbidity and loneliness, would be useful in guiding interventions targeted at loneliness, in romantic relationships. In fact, few interventions have focused on how to create safe relationships, healthy boundaries, and enhance protective factors, in romantic relationships, in emerging adulthood, despite their importance on mental and physical health (Braithwaite et al. 2010). The identification of different mediators would allow the creation of tailored interventions that could meet each couple's attachment needs and decrease the negative feelings in couples with an insecure attachment (Wei et al. 2005c).

Present Study

The present study analyzed the relationship among insecure attachment styles, infidelity, loneliness, taking in consideration also relationship satisfaction, prayer for a partner, physical and psychological morbidity, in young couples involved in romantic relationships. The purpose was to provide a model based on the relationships among the variables described earlier. Although the literature has provided empirical evidence for the relationship between two or three of these variables (e.g. attachment and loneliness; 
attachment and health; attachment and infidelity), no model has put together the relationships among attachment, infidelity, and loneliness considering the impact of relationship satisfaction, prayer (coping mechanism), and health. Such a model would have great heuristic interest for clinical interventions in couples therapy. In fact, attachment insecurity may contribute to interpersonal problems, (Wei et al. 2005c) with infidelity being the third most difficult common problem in couple therapy (Whisman et al. 1997).

The following model (Fig. 1) provides a pictorial summary of the hypothesized direct and indirect relationships described earlier. In particular, it shows the hypothesized mechanisms by which attachment styles and infidelity impact loneliness in young adults.

\section{Method}

Participants and Procedure

Participants were students in an introductory course on family development at a large university in the Southeastern United States. The class is required for several majors and is also an option for meeting liberal studies requirements, so students represent all colleges and majors on campus. Participation in the study was one of multiple options for students to obtain extra course credit. The study was approved by the Institutional Review Board and informed consent was obtained before participants, as part of a larger study, completed a battery of questionnaires that included the measures described below. This study examined only students $(\mathrm{n}=345)$ who were in a romantic relationship. The average age of participants was $19.46(\mathrm{SD}=1.92)$ and $25 \%$ were males. After providing informed consent participants completed a set of instruments.

Instruments

Short-Form UCLA Loneliness Scale (ULS-8)

Loneliness was measured by the Short-Form Measure of Loneliness (Hays and DiMatteo 1987). The scale uses eight items to assess loneliness ("I lack companionship", "There is no one I can turn to", "I am an outgoing person", "I feel left out", "I feel isolation from others", "I can find companionship when I want it", "I am unhappy being so withdrawn", "People are around me but not with me") in a 4-point Likert scale with values ranging from "never" to "always". High scores indicate more feelings of loneliness. Cronbach's alpha was .84 in this sample.

\section{Relationship Satisfaction Scale}

The relationship satisfaction scale is a 4-item measure that assesses satisfaction in a relationship (Funk and Rogge 2007). Scale items are: "How rewarding is your relationship with your partner?", "How well does your partner meet your needs?", "To what extent has your relationship met your original expectations?", and "To what extent has your relationship met your original expectations?" Items are rated using a Likert-type format from 0 (not at all) to 5 (completely). High scores indicate more relationship satisfaction. In the current sample Cronbach alpha was .93. 


\section{Rotterdam Symptom Checklist}

This checklist assesses psychological symptoms (15 items) and physical symptoms (14 items) (De Haes et al. 1996). Psychological morbidity items include depressed mood, despair regarding the future, worrying and anxiety. Examples of physical symptoms include fatigue, tiredness, headaches, dizziness and difficulty in sleeping. Higher scores indicate higher psychological or physical morbidity respectively. In this sample, the subscales of psychological and physical morbidity booth yielded a Cronbach alpha of .86 .

\section{Prayer for Partner Scale}

To measure prayer for partner a 4-item measure was used. Scale items include: "I pray for the well-being of my romantic partner"; "I pray that good things will happen for my partner"; "I ask God to watch over my partner" and "I pray for my partner to reach her goals". Items are scored using a 1 (never) to 5 (very frequently) Likert scale. High scores indicate higher frequency of prayer. Cronbach alpha was .97 in this sample.

\section{Infidelity Scale}

This instrument includes 10 -items that asses infidelity in dating relationships. The scale includes an emotional and physical infidelity subscale (Drigotas et al. 1999). Participants were informed to think of a person that they were most attracted to besides their partner. They were then asked ten questions about their level of attraction (e.g., How attractive did you find this person?): arousal (e.g., How much arousal did you feel in their presence?), emotional engagement (e.g., How emotionally intimate were you with this person?) and physical involvement (e.g., How physically intimate were you with this person?). Items regarding attraction are scored on a 8-point Likert scale; 0 (not at all attractive) to 7 (extremely attractive), those regarding $\mathrm{f}$ arousal are scored on a 8-point Likert scale; 0 (none) to 7 (a great deal) and finally emotional engagement is scored on a 8-point Likert scale from 0 (not at all) to 7 (extremely). High score indicate more infidelity. Cronbach alpha was .96 in the current sample.

\section{The Experiences in Close Relationship Scale (ECR)-Short Form}

To measure attachment styles, the Experiences in Close Relationships-Short form (ECR-S; Wei et al. 2007) was used. The ECR-S contains 12 items divided into two subscales. The attachment anxiety subscale (six items) measures fear of abandonment or rejection from others (e.g., my desire to be very close sometimes scares people away) and the avoindant attachment subscale (six items) assesses fear of intimacy, discomfort with closeness and self-reliance (e.g. "My desire to be very close sometimes scares people away.") Items are rated using a Likert scale ranging from 0 (disagree strongly) to 6 (agree strongly). High scores in each subscale indicate more anxious or avoidant attachment style, respectively. In the present study, coefficient alpha was .88 for the anxiety attachment style, and .91 for the avoidance attachment style.

\section{Data Analysis}

In order to find means and standard deviations for each measure, descriptive statistics were used. To test the relationships among the variables, pearson correlation were performed. 
Finally, Mplus 5.1 (Muthén and Muthén 1998-2010) was used to test the SEM proposed model. Nonsignificant paths were dropped and based on the modificantion indices on the Mplus output, some paths were added to increase model-data fit.

\section{Results}

Relationships Among Loneliness, Attachment, Prayer, Morbidity and Infidelity

As expected, loneliness was positively related to avoidant $(\mathrm{r}=.22)$, and anxious attachment $(\mathrm{r}=.37)$, physical morbidity $(\mathrm{r}=.41)$ and psychological morbidity $(\mathrm{r}=.36)$ and negatively related to relationship satisfaction $(r=-.265)$. Interestingly, praying for the partner was positively related to satisfaction with the relationship $(r=.13)$ and negatively associated with infidelity $(\mathrm{r}=-.12)$ and anxious attachment $(\mathrm{r}=-.13)$. Infidelity was negatively associated with relationship satisfaction $(\mathrm{r}=-.26)$ and positively associated with insecure attachment (avoiant; $\mathrm{r}=.26$; anxious $\mathrm{r}=.12$ ). Physical morbidity was positively related to avoidant and anxious attachment $(\mathrm{r}=.13 ; \mathrm{r}=.33)$ and the same was true for psychological morbidity $(\mathrm{r}=.21 ; \mathrm{r}=.36)$. Physical and psychological morbidity were negatively related to satisfaction ( $\mathrm{r}=-.11 ; \mathrm{r}=-16$, respectively), and psychological morbidity was negatively related to avoidant and anxious attachment $(\mathrm{r}=-.56 ; \mathrm{r}=-.32$, respectively). Tables 1 and 2 show the descriptive statistics and the correlations among the variables.

\section{Structural Equation Model}

The final model (Fig. 2) showed a good fit to the data, $\chi^{2}(14)=17.206, p>.05$, $\mathrm{CFI}=.995$, RMSEA $=.025$, and SRMR $=.027$ (Fig. 2). Only the significant direct effects are presented in the figure. The numerical values represent standardized direct effects for the final model. For example, there were two significant direct effects from Infidelity: direct effect on Satisfaction and direct effect on Loneliness. The size of the direct effects ranged from .09 to .73 , in absolute values. Some of the direct effects were negative, for example the direct effect from Infidelity to Satisfaction (the value of the direct effect was -.12 with a standard error of .05 i.e. one standard deviation (SD) increase in Infidelity was related to .12 SD decrease in Satisfaction).There were also positive direct effects in the model. For example, the value of direct effect from Psychology to Physical morbidity was .73 with a standard error of .03 (one SD increase in Psychology morbidity was related to .73 SD increase in Physica Morbidity).

Table 1 Descriptive statistics

\begin{tabular}{lrllr}
\hline & Minimum & Maximum & Mean & SD \\
\hline Loneliness & 8 & 28 & 14.79 & 4.51 \\
Prayer P & 4 & 20 & 12.31 & 5.70 \\
Infidelity & 10 & 80 & 38.75 & 22.06 \\
Physical morbidity & 7 & 28 & 13.46 & 4.35 \\
Psychological morbidity & 22 & 77 & 33.78 & 7.89 \\
Relationship satisfaction & 4 & 25 & 20.25 & 4.35 \\
Avoidant attachment & 6 & 36 & 12.81 & 6.85 \\
Anxious attachment & 6 & 38 & 19.13 & 7.19 \\
\hline
\end{tabular}




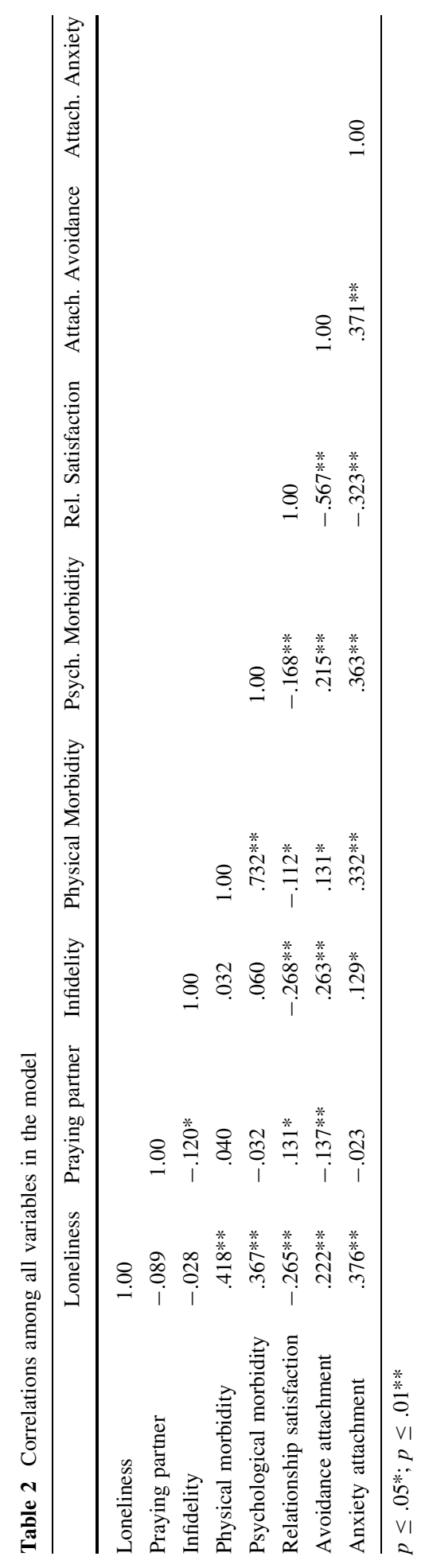




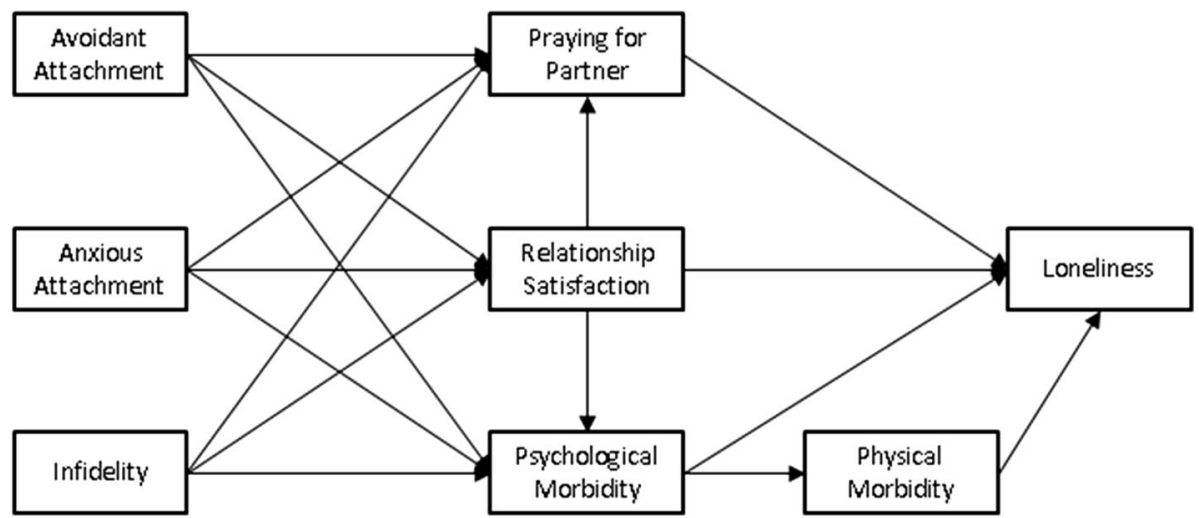

Fig. 1 Proposed model

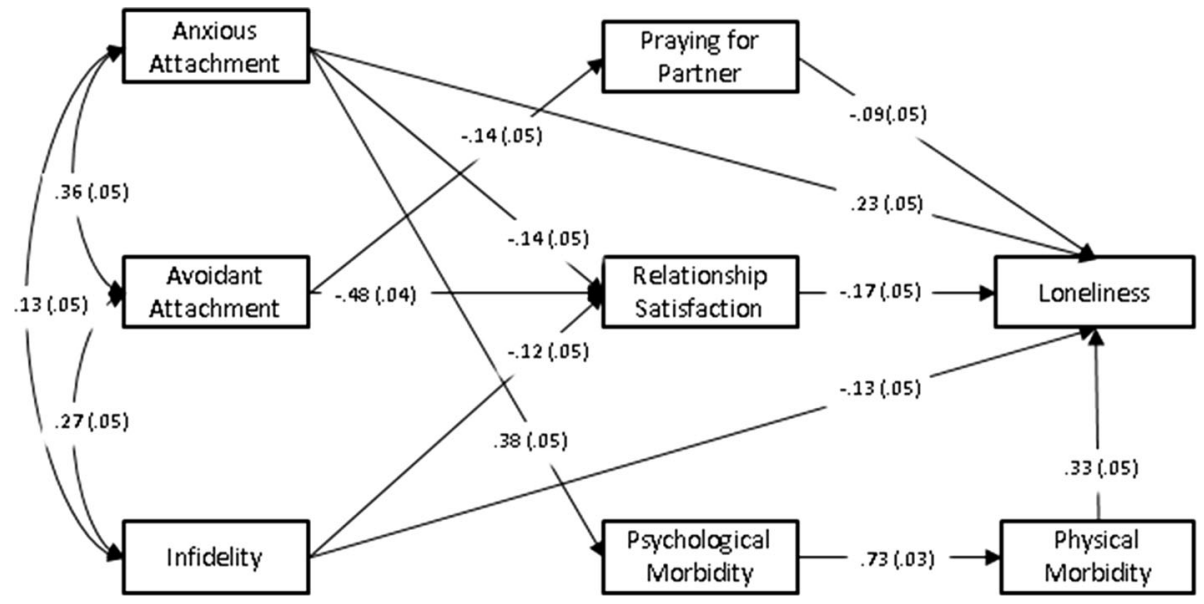

Fig. 2 Final model

As Table 3 shows, satisfaction with one's relationship mediated the relationship between the avoidant attachment style and loneliness, and between infidelity and loneliness. Physical morbidity mediated the relationship between psychological morbidity and loneliness, and psychological morbidity mediated the relationship between anxious attachment style and physical morbidity.

Table 3 Significant standardized indirect effects for the mediations

\begin{tabular}{lll}
\hline Path (Independent $\rightarrow$ Outcome & Mediator & \\
\hline Avoidant attachment $\rightarrow$ Loneliness & Relationship satisfaction & $.082^{* *}$ \\
Psychological morbidity $\rightarrow$ Loneliness & Physical morbidity & $.243^{* *}$ \\
Infidelity $\rightarrow$ Loneliness & Relationship satisfaction & $.021^{*}$ \\
Anxious attachment $\rightarrow$ Physical Morbidity & Psychological morbidity & $.273^{* *}$ \\
\hline
\end{tabular}

$* p \leq .05 ; * * p \leq .01$ 
Praying for the partner was hypothesized to mediate the relationship between avoidant attachment style and loneliness but this mediational relationship was not found. Also, relationship satisfaction and prayer for the partner did not mediate the relationship between anxious style and infidelity. Contrary to the expectations, psychological and physical morbidity did not mediate the relationship between infidelity and loneliness.

\section{Discussion}

This study examined potential mediators (relationship satisfaction, prayer, and psychological morbidity) between attachment and loneliness, infidelity and loneliness, and between morbidity and loneliness. Only relationship satisfaction and psychological morbidity mediated the relationship between attachment and loneliness. Relationship satisfaction also mediated the relationship between infidelity and loneliness. Previous researchers have not examined the potential mediating role of relationship satisfaction and prayer, but the link between attachment and loneliness is consistent with Weiss' (1973) model and other findings (e.g., DiTommaso and Spinner 1997; Hazan and Shaver 1987; Wei et al. 2005c). In fact, attachment is a good predictor of romantic loneliness. Dating couples, with high levels of avoidant attachment, showed less satisfaction with their relationships and experienced feelings of loneliness. In addition, dating couples with high levels of avoidant attachment prayed less for their partner (direct effect) and the participants who prayed for their partners experienced less feelings of loneliness (direct effect) but prayer did not emerge as a mediating variable. On the other hand, dating couples with high levels of attachment anxiety showed more feelings of loneliness (direct effect) and more psychological morbidity. The present results expand the literature on attachment by presenting empirical evidence regarding the mechanisms linking anxious and avoidant attachment styles to loneliness, showing that they are different.

The present result supports partially the initial, hypothesized model since only relationship satisfaction was found to be a mediator between the avoidant attachment style and loneliness. This result is consistent with our hypothesis that predicted partners with insecure attachments to show less relationship satisfaction, in their dating relationships. In fact, the results showed that partners with avoidant attachment were less satisfied with their relationships. This finding is also consistent with previous research (e.g., Mikulincer and Shaver 2007) Feeney's (2002) found of a strong association between relationship satisfaction and avoidant attachment, in dating couples (see Mikulincer et al. 2002 for a review.) In fact, partners with high levels of avoidant attachment fear closeness/intimacy in their relationships and these interpersonal deficits may contribute to feelings of dissatisfaction and loneliness (Fraley et al. 2000). Some studies found both insecure attachment styles to be positively relayed to loneliness (Deniz et al. 2005; Wei et al. 2005a, b). Our findings are, therefore, consistent with prior research in dating couples. However, the results also showed that different mechanisms are at play for each form of attachment insecurity.

In this study, praying for the partner did not mediate the relationship between attachment style and loneliness. However, partners high in avoidant attachment style prayed less for their partner. This finding is consistent with Kirkpatrick's (1992) correspondence theory in which level of prayer was related to attachment style. Avoidant partners are more likely to describe themselves as agnostic (Kirkpatrick and Shaver 1990) and engage less in prayer for their partner (Byrd and Boe 2001). The finding that prayer for the partner was associated with less loneliness is also consistent with other findings regarding the impact of general prayer (Ismail and Desmukh 2012; Poloma and Pendleton 1989; Rokach et al. 2004). 
It comes as no surprise that partners who are more satisfied with their relationship, and have an insecure attachment style, may show more psychological morbidity. In fact, research shows a relationship between anxiety attachment and psychological morbidity (Mallinckrodt and Wei 2005; Wei et al. 2003, 2004). In the beginning of a relationship, relationship satisfaction, in an anxious partner, may be related to the idealization of the partner, a pattern that is so common in the anxious attachment style (Feeney and Noller 1991) reflecting the first stage of a romantic relationship. Therefore, even when a person feels satisfied with the relationship, the person may be aware of their fear of losing the partner or fear that the partner may not be able to provide what they need feeling, therefore, lonely and, as a result, praying more. Avoidant couples pray less (negative link in the direct effect) and, in this case, prayer does not mediate the relationship between attachment and loneliness. This result follows previous studies that showed avoidant individuals to keep their distance from significant others, in order to protect themselves from disappointments, and this protection may include their relationship with the deity (Byrd and Boe 2001).

The present study showed that unfaithful partners reported less satisfaction and more loneliness which were consistent with prior research (e.g., Baumeister et al. 1995). Partners, who engage in an extradyadic relationship, showed more dissatisfaction with their relationships and more psychological distress. Consistent with the initial model, infidelity was negatively related to loneliness (direct effect) but this finding may seem surprising in the light of previous research (e.g., Allen et al. 2005) that suggested a positive relationship between extramarital involvement and loneliness. However, in our sample those involved in extradyadic relationships felt less lonely. This result is consistent with Hall and Fincham (2009) and Wiggins and Lederer (1984) who found unfaithful partners to feel satisfied and not lonely, making use of the opportunities they had and adapting their beliefs, toward infidelity, by rationalizing their behavior and comforting themselves psychologically. As a result, one understands why these partners may not report loneliness (Aronson et al. 1995).

In our study, psychological morbidity was not a mediator between infidelity and loneliness, and physical morbidity did not mediate the relationship between psychological morbidity and loneliness as predicted in the initial model. We believe these results have to do with the fact that, in this sample, infidelity was not perceived as a "bad thing" and, in fact, resulted in less loneliness. However, psychological morbidity did mediate the relationship between anxious style and physical morbidity. This result is in accordance with the literature that showed anxiety and depressive symptoms associated with insecure attachments (Wei et al. 2003, 2004; Lee and Hankin 2009). In fact, the association between psychological and physical morbidity was the strongest in the model but none of the variables were mediators between attachment style and loneliness. This result may reflect a floor effect as physical morbity, in our sample, was quite low. Also, the sample in the present study was very young (mean age of 19) and this may explain why even though previous research has found loneliness to be associated with physical health, particularly with accelerated physiological aging (Hawkley and Cacioppo 2007), cardiovascular health risk, morbidity, mortality (Caspi et al. 2006) and physical symptoms (DeBerard and Kleinknecht 1995), our study did not find such a relationship. Therefore, future research should replicate the results with older couples involved in a romantic relationship.

\section{Conclusion}

In summary, avoidantly attached individuals showed greater loneliness when dissatisfied in their dating relationship whereas anxiously attached individuals showed more physical 
morbidity (more health symptoms) when they reported more psychological morbidity. This result makes sense when one recalls that the anxiety system becomes activated when partners have something they like and fear to lose. For so many couples, attachment and connection occur easily, at the beginning of the relationship, when all the endorphins in the brain are supporting the intensity of "falling in love" and losing the relationship feels unbearable. This is likely to be true, in our sample, as it includes very young adults involved in romantic relationships.

Therapists need to understand that in adulthood, the couple relationship is a primary attachment relationship that provides an opportunity for growth and protection. When a person has an insecure attachment being satisfied with the partner may buffer the person from experiencing loneliness or psychological morbidity. Therefore, assessing individual attachment styles may be paramount in therapy, particularly, in couples with a long relationship since maintaining a positive bond becomes harder as the relationship progresses. With time, the impact of an insecure attachment style may become stronger and the couple may start using unsuccessful coping strategies since the anxiety system has been activated (Locke 2008). In such a situation, avoidantly attached individuals may become more distant from the partner or develop a pervasive conflict pattern that may impact loneliness, psychological and physical morbidity. Anxiously attached individuals may tend to idealize the partner and desire the partner to reciprocate this feeling. At the beginning of the relationship extensive contact and declarations of affection are more frequent and the anxious attached partner may experience a sense of security and a sense of self that makes them feel more satisfied with the relationship. However, as time goes by, anxious partners may invest even more in the relationship, believing that this will provide them even more attention and affection. However, after being disappointed and feeling less satisfied with the relationship, anxiously attached individuals may report physical symptoms when they feel more psychological morbidity, according to the results. Since physical morbidity is positively associated with loneliness, these individuals will also report more loneliness. An assessment of attachment style is, therefore, important and should be part of couple therapy regardless of the model of therapy that inspires the work of the family therapist.

\section{Limitations}

Several limitations of the present study should be noted. First, the sample consisted of undergraduate students, in dating relationships. Married couples may have distinct experiences concerning relationship satisfaction and prayer (e.g. because of greater commitment and investment). The study was cross sectional and to better understand direction of effects, future studies should use a longitudinal design particularly, regarding the link between infidelity, relationship satisfaction, psychological morbidity and physical health symptoms. It is also important to assess relationship satisfaction at several stages of the relationship and not only after infidelity (Blow and Hartnett 2005).

Finally, future research should replicate these results with a sample of distressed couples and in individuals not pursing higher education.

Acknowledgments This research was supported by Grant Number 90FE0022 from the United States Department of Health and Human Services awarded to the last author. 


\section{References}

Allen, E. S., Atkins, D., Baucom, D. H., Snyder, D., Gordon, K. C., \& Glass, S. P. (2005). Intrapersonal, interpersonal, and contextual factors in engaging in and responding to extramarital involvement. Clinical Psychology: Science and Practice, 12, 101-130. doi:10.1093/clipsy.bpi0.

Allen, E. S., \& Baucom, D. H. (2004). Adult attachment and patterns of extradyadic involvement. Family Process, 43, 467-488. doi:10.1111/j.1545-5300.2004.00035.x.

Allen, E. S., \& Baucom, D. H. (2006). Dating, marital, and hypothetical extradyadic involvements: How do they compare? Journal of Sex Research, 43, 307-317. doi:10.1080/00224490609552330.

Aronson, J., Blanton, H., \& Cooper, J. (1995). From dissonance to disidentification: Selectivity in the selfaffirmation process. Journal of Personality and Social Psychology, 68(6), 986-996. doi:10.1037/00223514.68.6.986.

Atkins, D. C., Baucom, D. H., \& Jacobson, N. S. (2001). Understanding infidelity: Correlates in a national random sample. Journal of Family Psychology, 15, 735-749. doi:10.1037/0893-3200.15.4.735.

Barta, W. D., \& Kiene, S. M. (2005). Motivations for infidelity in heterosexual dating couples: The roles of gender, personality differences, and sociosexual orientation. Journal of Social and Personal Relationships, 22, 339-360. doi:10.1177/0265407505052440.

Baumeister, R. F. (1998). The self. In D. T. Gilbert, S. T. Fiske, \& G. Lindzey (Eds.), Handbook of social psychology (4th ed., pp. 680-740). New York: McGraw-Hill.

Baumeister, R. F., Stillwell, A. M., \& Heatherton, T. F. (1995). Personal narratives about guilt: Role in action control and interpersonal relationships. Basic and Applied Social Psychology, 17, 173-198. doi:10.1080/01973533.1995.9646138.

Bernardon, S., Babb, K. A., Hakim-Larson, J., \& Gragg, M. (2011). Loneliness, attachment, and the perception and use of social Support in university students. Canadian Journal of Behavioural Science, 43(1), 40-51. doi:10.1037/a0021199.

Besser, A., \& Priel, B. (2003). A multisource approach to self-critical vulnerability to the truth depression: The moderating role of attachment. Journal of Personality, 71, 515-555. doi:10.1111/1467-6494. 7104002 .

Blow, A. J., \& Hartnett, K. (2005). Infidelity in committed relationships II: A substantive review. Journal of Marital and Family Therapy, 31, 217-233.

Bogaert, A. F., \& Sadava, S. (2002). Adult attachment and sexual behavior. Personal Relationships, 9, 191-204. doi:10.1111/1475-6811.00012.

Bogdan-Raque, T. L., Ericson, S. K., Jackson, J., Martin, H. M., \& Byryan, N. A. (2011). Journal of Counseling Psychology, 58(2), 272-278. doi:10.1037/a0023041.

Bowlby, J. (1973). Affectional bonds: Their nature and origin. In R. S. Weiss (Ed.), Loneliness: The experience of emotional and social isolation (pp. 38-52). Cambridge: MIT Press.

Bowlby, J. (1980). Attachment and loss. Loss: Sadness and depression (Vol. III). London: Hogarth Press.

Braithwaite, S. R., Lambert, N. M., Fincham, F., \& Pasley, K. (2010). Does college-based relationships education decrease extradyadic involvement in relationships? Journal of Family Psychology, 24(6), 740-745. doi:10.1037/a0021759.

Brown, E. M. (1991). Patterns of infidelity and their treatment. New York: Brunner/Mazel.

Butler, M. H., Stout, J. A., \& Gardner, C. (2002). Prayer as a conflict resolution ritual: Clinical implications of religious couples' report of relationship softening, healing perspective, and change responsibility. The American Journal of Family Therapy, 30, 19-37. doi:10.1080/019261802753455624.

Byrd, K. R., \& Boe, A. D. (2001). The correspondence between attachment dimensions and prayer in college students. The International Journal for the Psychology of Religion, 11, 9-24. doi:10.1207/ S15327582IJPR1101 02.

Byrd, K. R., Hageman, A., \& Isle, D. B. (2007). Intrinsic motivation and subjective well-being: The unique contribution of intrinsic religious motivation. The International Journal for the Psychology of Religion, 17, 141-156. doi:10.1207/S15327582IJPR1101_02.

Campbell, L., Simpson, J. A., Boldry, J., \& Kashy, D. A. (2005). Perceptions of conflict and support in romantic relationships: The role of attachment anxiety. Journal of Personality and Social Psychology, 88, 510-531. doi:10.1080/10508610701244155.

Cann, A., Norman, M. A., Welbourne, J. L., \& Calhoun, L. G. (2008). Attachment styles, conflict styles and humour styles: Interrelationships and associations with relationship satisfaction. European Journal of Personality, 22, 131-146. doi:10.1002/per.666.

Caspi, A., Harrington, H., Moffitt, T. E., Milne, B. J., \& Poulton, R. (2006). Socially isolated children 20 years later: Risk of cardiovascular disease. Archives of Pediatrics and Adolescent Medicine, 160 , 805-811. doi:10.1001/archpedi.160.8.805. 
Ciechanowski, P. S., Walker, E. A., Katon, W. J., \& Russo, J. E. (2002). Attachment theory: A model for health care utilization and somatization. Psychosomatic Medicine, 64, 660-667. doi:10.1097/01.PSY. 0000021948.90613 .76$.

Collins, N. L., \& Read, S. J. (1990). Adult attachment, working models, and relationship quality in dating couples. Journal of Personality andSocial Psychology, 58, 644-663. doi:10.1037/0022-3514.58.4.644.

Davis, D., Shaver, P. R., \& Vernon, M. L. (2004). Attachment style and subjective motivations for sex. Personality and Social Psychology Bulletin, 30, 1076-1090. doi:10.1177/0146167204264794.

De Haes, J. C. J. M., Olschewski, M., Fayers, P., et al. (1996). Measuring the quality of life of cancer patients with the Rotterdam symptom checklist (RSCL): A manual. Groningen: Northern Centre for Healthcare Research.

de Jong Gierveld, J., Broese van Groenou, M., Hoogendoorn, A. W., \& Smit, J. H. (2009). Quality of marriages in later life and emotional and social loneliness. The Journal of Gerontology, 64, 497-506. doi:10.1093/geronb/gbn043.

DeBerard, M. S., \& Kleinknecht, R. A. (1995). Loneliness, duration of loneliness, and reported stress symptomatology. Psycholological Reports, 76(3), 1363-1369. doi:10.2466/pr0.1995.76.3c.1363.

Deniz, M. E., Hamarta, E., \& Arı, R. (2005). An investigation of social skills and loneliness levels of university students with respect to their attachment styles in a sample of Turkish students. Social Behavior and Personality: An International Journal, 33, 19-30. doi:10.2224/sbp.2005.33.1.19.

DiTommaso, E., Brennen-McNulty, C., Ross, L., \& Burgess, M. (2003). Attachment styles, social skills, and loneliness in young adults. Personality and Individual Differences, 35, 303-312. doi:10.1016/S01918869(02)00190-3.

DiTommaso, E., \& Spinner, B. (1997). Social and emotional loneliness: A re-examination of Weiss' typology of loneliness. Personality and Individual Differences, 22, 417-427. doi:10.1016/S01918869(96)00204-8

Drigotas, S. M., Safstrom, C. A., \& Gentilia, T. (1999). An investment model prediction of dating infidelity. Journal of Personality and Social Psychology, 77, 509-524. doi:10.1037/0022-3514.77.3.509.

Dudley, M. G., \& Kosinski, F. A. (1990). Religiosity and marital satisfaction: A research note. Review of Religious Research, 32, 78-86. Retrieved from http://www.jstor.org/stable/3511329.

Feeney, J. A. (2000). Implications of attachment style for patterns of health and illness. Child Care Health Development, 26, 277-288. doi:10.1046/j.1365-2214.2000.00146.x.

Feeney, J. A. (2002). Attachment, marital interaction, and relationship satisfaction: A diary study. Personal Relationships, 9, 39-55. doi:10.1111/1475-6811.00003.

Feeney, J. A., \& Noller, P. (1990). Attachment style as a predictor of adult romantic relationships. Journal of Personality and Social Psychology, 58, 281-291. doi:10.1037/0022-3514.58.2.281.

Feeney, J. A., \& Noller, P. (1991). Attachment style and verbal descriptions of romantic partners. Journal of Social and Personal Relationships, 8, 187-215. doi:10.1111/1475-6811.00003.

Fincham, F. D., \& Beach, S. R. H. (1999). Conflict in marriage: Implications for working with couples. Annual Review of Psychology, 50, 47-77. doi:10.1146/annurev.psych.50.1.47.

Fincham, F. D., Beach, S. R. H., Lambert, N. M., Stillman, T. F., \& Braithwaite, S. R. (2008). Spiritual behaviors and relationship satisfaction: A critical analysis of the role of prayer. Journal of Social and Clinical Psychology, 27, 362-388. doi:10.1521/jscp.2008.27.4.362.

Fincham, F. D., Lambert, N. M., \& Beach, S. R. H. (2010). Faith and unfaithfulness: Can praying for your partner reduce infidelity? Journal of Personality and Social Psychology, 99, 649-659. doi:10.1037/ a0019628.

Fitzpatrick, J., Feng, D., \& Crawford, D. (2003). A contextual model analysis of women's social competence, affective characteristics, and satisfaction in premarital relationships. Journal of Family Communication, 3, 107-122. doi:10.1207/S15327698JFC0302_03.

Flora, J., \& Segrin, C. (2000). Relationship development in dating couples: Implications for relational satisfaction and loneliness. Journal of Social and Personal Relationships, 17, 811-825. doi:10.1177/ 0265407500176006.

Fraley, R. C., Waller, N. G., \& Brennan, K. A. (2000). An item response theory of self-report measures of adult attachment. Journal of Personality and Social Psychology, 78, 350-365. doi:10.1037/0022-3514. 78.2.350.

Funk, J. L., \& Rogge, R. D. (2007). Testing the ruler with item response theory: Increasing precision of measurement for relationship satisfaction with the Couples Satisfaction Index. Journal of Family Psychology, 21, 572-583. doi:10.1037/0893-3200.21.4.572.

Glass, S. P., \& Wright, T. L. (1997). Reconstructing marriages after the trauma of infidelity. In K. Halford \& H. Markman (Eds.), Clinical handbook of marriage and couples Interventions. New York: Wiley. 
Granqvist, P. (1998). Religiousness and perceived childhood attachment: On the question of compensation or correspondence. Journal for the Scientific Study of Religion, 37, 350-367. http://www.jstor.org/ stable/1387533.

Griffin, D., \& Bartholomew, K. (1994). Models of the self and other: Fundamental dimensions underlying measures of adult attachment. Journal of Personality and Social Psychology, 67, 430-445. doi:10. 1037/0022-3514.67.3.430.

Hall, J. H., \& Fincham, F. D. (2009). Psychological distress: Precursor or consequence of dating infidelity? Personality and Social Psychology Bulletin, 35, 143-159. doi:10.1177/0146167208327189.

Hawkley, L. C., \& Cacioppo, J. T. (2007). Aging and loneliness: Downhill quickly? Current Directions in Psychological Science, 16, 187-191. doi:10.1111/j.1467-8721.2007.00501.x.

Hays, R. D., \& DiMatteo, M. T. (1987). A short-form measure of loneliness. Journal of Personality Asseement, 51, 69-81. doi:10.1207/s15327752jpa5101_6.

Hazan, C., \& Shaver, P. (1987). Romantic love conceptualized as an attachment process. Journal of Personality and Social Psychology, 52, 511-524. doi:10.1037/0022-3514.52.3.511.

Hecht, D. T., \& Baum, S. K. (1984). Loneliness and attachment patterns in young adults. Journal of Clinical Psychology, 40, 193-197. doi:10.1002/1097-4679(198401)40:1<193:AID-JCLP2270400136>3.0. $\mathrm{CO} ; 2-2$.

Ismail, Z., \& Desmukh, S. (2012). Religiosity and psychological well-being. International Journal of Business and Social Science, 3, 20-28. http://www.ijbssnet.com/update/index.php/side-archive. html?id=1294.

Keelan, J. P. R., Dion, K. K., \& Dion, K. L. (1998). Attachment style and relationship satisfaction: Test of a self-disclosure explanation. Canadian Journal of Behavioural Science, 30, 24-35. doi:10.1037/ h0087055.

Kirkpatrick, L. A. (1992). An attachment-theory approach to the psychology of religion. International Journal for the Psychology of Religion, 2, 3-28. doi:10.1207/s15327582ijpr0201_2.

Kirkpatrick, L. A. (1995). Attachment theory and religious experience. In R. W. Hood (Ed.), Handbook of religious experience (pp. 446-475). Birmingham, AL: Religious Education Press.

Kirkpatrick, L. A. (1998). God as a substitute attachment figure: A longitudinal study of adult attachment style and religious change in college students. Personality and Social Psychology Bulletin, 24, 961-973. doi:10.1207/s15327582ijpr0201_2.

Kirkpatrick, L. A. (1999). Attachment and religious representations and behavior. In J. Cassidy \& P. R. Shaver (Eds.), Handbook of attachment. New York: Guilford.

Kirkpatrick, L. A., \& Davis, E. D. (1994). Attachment style, gender, and relationship stability: A longitudinal analysis. Journal of Personality and Social Psychology, 66, 502-512. doi:10.1037/0022-3514.66. 3.502 .

Kirkpatrick, L. A., \& Hazan, C. (1994). Attachment styles and close relationships: A 4 year prospective study. Personal Relationships, 1, 123-142. doi:10.1111/j.1475-6811.1994.tb00058.x.

Kirkpatrick, L. A., \& Shaver, P. R. (1990). Attachment theory and religion: Childhood attachments, religious beliefs, and conversion. Journal for the Scientific Study of Religion, 29, 315-334. http://www. jstor.org/stable/1386461.

Kirkpatrick, L. A., \& Shaver, P. R. (1992). An attachment-theoretical approach to romantic love and religious belief. Personality and Social Psychology Bulletin, 18, 266-275. doi:10.1177/ 0146167292183002.

Kobak, R., \& Sceery, A. (1988). Attachment in late adolescence: Working models, affect regulation, and representations of self and others. Child Development, 59, 135-146. http://www.jstor.org/stable/ 1130395.

Lambert, N. M., \& Dollahite, D. C. (2006). How religiosity helps couples prevent, resolve, and overcome marital conflict. Family Relations, 55, 439-449. doi:10.1111/j.1741-3729.2006.00413.x.

Lambert, N. M., Fincham, F. D., LaVallee, D. C., \& Brantley, C. W. (2012). Praying together and staying together: Couple prayer and trust. Psychology of Religion and Spirituality, 4, 1-9. doi:10.1037/ a0023060.

Larose, S., \& Bernier, A. (2001). Social support processes: Mediators of attachment state of mind and adjustment in late adolescence. Attachment and Human Development, 3, 96-120. doi:10.1080/ 14616730010024762.

Lee, A., \& Hankin, B. L. (2009). Insecure attachment, dysfunctional attitudes, and low self-esteem predicting prospective symptoms of depression and anxiety during adolescence. Journal of Clinical Child Adolescent Psychology, 38(2), 219-231. doi:10.1080/15374410802698396.

Levine, M. (2008). Prayer as coping: A psychological analysis. Journal of Health Care Chaplaincy, 15, 80-98. doi:10.1080/08854720903113424. 
Locke, K. (2008). Attachment styles and interpersonal approach and avoidance goals in everyday couple interactions. Personal Relationships, 15, 359-374. doi:10.1111/j.1475-6811.2008.00203.x.

Lopez, F. G., Mauricio, A. M., Gormley, B., Simko, T., \& Berger, E. (2001). Adult attachment orientations and college student distress: The mediating role of problem coping styles. Journal of Counseling \& Development, 79, 459-464. doi:10.1002/j.1556-6676.2001.tb01993.x.

Lopez, F. G., Mitchell, P., \& Gormley, B. (2002). Adult attachment and college student distress: Test of a mediational model. Journal of Counseling Psychology, 49, 460-467. doi:10.1037/0022-0167.49.4.460.

Mallinckrodt, B., \& Wei, M. (2005). Attachment, social competencies, social support, and psychological distress. Journal of Counseling Psychology, 52, 358-367. doi:10.1037/0022-0167.52.3.358.

Maltby, J., Lewis, C. A., \& Day, L. (1999). Religious orientation and the psychological well-being: The role of the frequency of personal prayer. British Journal of Health Psychology, 4, 363-378. doi:10.1348/ 135910799168704

Man, K., \& Hamid, P. N. (1998). The relationship between attachment prototypes, self-esteem, loneliness and causal attributions in Chinese trainee teachers. Personality and Individual Differences, 24, 357-371. doi:10.1016/S0191-8869(97)00185-2.

Maunder, R. G., \& Hunter, J. J. (2008). Attachment relationships as determinants of physical health. The Journal of the American Academy of Psychoanalysis and dynamic Psychiatry, 36, 11-32. doi:10.1521/ jaap.2008.36.1.11.

Mikulincer, M., Florian, V., Cowan, P. A., \& Cowan, C. P. (2002). Attachment security in couple relationships: A systemic model and its implications for family dynamics. Family Process, 41(3), 405-434. doi:10.1111/j.1545-5300,2002.41309.x.

Mikulincer, M., \& Shaver, P. R. (2007). Attachment in adulthood: Structure, dynamics, and change. New York: The Guilford Press.

Muthén, L. K., \& Muthén, B. O. (1998-2010). Mplus user's guide (6th ed.). Los Angeles, CA: Muthén \& Muthén.

Poloma, M. M., \& Pendleton, B. F. (1989). Exploring types of prayer and quality of life: A research note. Review of Religious Research, 31, 46-53. http://www.jstor.org/stable/3511023.

Puig, J., Englund, M. M., Simpson, J. A., \& Collins, W. A. (2012). Predicting adult physical illness from infant attachment: A prospective longitudinal study. Health Psychology. Advance online publication. doi:10.1037/a0028889.

Rokach, A., Orzeck, T., \& Neto, F. (2004). Coping with loneliness in old age: A cross-cultural comparison. Current Psychology, 23, 124-137. doi:10.1007/BF02903073.

Roscoe, B., Cavanaugh, L. E., \& Kennedy, D. R. (1988). Dating infidelity: Behaviors, reasons, and consequences. Adolescence, 23, 35-43.

Rotenberg, K. J. (1994). Loneliness and interpersonal trust. Journal of Social and Clinical Psychology, 13, 152-173. doi:10.1521/jscp.1994.13.2.152.

Rusbult, C. E., Martz, J. M., \& Agnew, C. R. (1998). The investment model scale: Measuring commitment level, satisfaction level, quality of alternatives, and investment size. Personal Relationships, 5, 357-391. doi:10.1111/j.1475-6811.1998.tb00177.x.

Segrin, C., Powell, H. L., Givertz, M., \& Brackin, A. (2003). Symptoms of depression, relational quality, and loneliness in dating relationships. Personal Relationships, 10, 25-36. doi:10.1111/1475-6811. 00034 .

Shaaver, P. R., \& Hazan, C. (1989). Being lonely, falling in love: Perspectives from attachment theory. In M. Hojat \& R. Crandall (Eds.), Loneliness: Theory, research, and applications (pp. 105-124). Newbury Park, CA: Sage.

Sheppard, V. J., Nelson, E. S., \& Andreoli-Mathie, V. (1995). Dating relationships and infidelity: Attitudes and behaviors. Journal of Sex and Marital Therapy, 21, 202-212. doi:10.1080/00926239508404399.

Simpson, J. A. (1990). Influence of attachment styles on romantic relationships. Journal of Personality and Social Psychology, 59, 971-980. doi:10.1037/0022-3514.59.5.971.

Simpson, J. A., \& Rholes, W. S. (Eds.). (1997). Attachment theory and close relationships. New York: Guilford Press.

Snyder, D. K., Baucom, D. H., \& Gordon, K. C. (2008). An integrative approach to treating infidelity. The Family Journal, 16, 300-307. doi:10.1177/1066480708323200.

Spanier, G. B., \& Margolis, R. L. (1983). Marital separation and extramarital sexual behavior. Journal of Sex Research, 19, 23-48. doi:10.1080/00224498309551167.

Wearden, A., Lamberton N., Crook N., \& Walsh V. (2005). Adult attachment, alexithymia, and symptom reporting. An extension to the four category model of attachment. Journal of Psychosomatic Research, 58, 279-288. http://www.ncbi.nlm.nih.gov/pubmed/15865953. 
Wei, M., Heppner, P. P., \& Mallinckrodt, B. (2003). Perceived coping as a mediator between attachment and psychological distress: A structural equation modeling approach. Journal of Counseling Psychology, 50, 438-447. doi:10.1037/0022-0167.50.4.438.

Wei, M., Mallinckrodt, B., Russell, D. W., \& Abraham, W. T. (2004). Maladaptive perfectionism as a mediator and moderator between adult attachment and psychological distress. Journal of Counseling Psychology, 51, 201-212. doi:10.1037/0022-0167.51.2.201.

Wei, M., Russell, D. W., Mallinckrodt, B., \& Vogel, D. L. (2007). The Experiences in Close Relationships Scale (ECR) - Short Form: Reliability, validity, and factor structure. Journal of Personality Assessment, 88, 187-204. doi:10.1080/00223890701268041.

Wei, M., Russell, D. W., \& Zakalik, R. A. (2005a). Adult attachment, social self-efficacy, self-disclosure, loneliness, and subsequent depression for freshman college students: A longitudinal study. Journal of Counseling Psychology, 52(4), 602-614. doi:10.1037/0022-0167.52.4.602.

Wei, M., Shaffer, P. A., Young, S. K., \& Zakalik, R. A. (2005b). Adult attachment, shame, depression, and loneliness: The mediation role of basic psychological needs satisfaction. Journal of Counseling Psychology, 52, 591-601. doi:10.1037/0022-0167.52.4.591.

Wei, M., Vogel, D. L., Ku, T.-Y., \& Zakalik, R. A. (2005c). Adult attachment, affect regulation, negative mood, and interpersonal problems: The mediating roles of emotional reactivity and emotional cutoff. Journal of Counseling Psychology, 52, 14-24. doi:10.1037/0022-0167.52.1.14.

Weiss, R. S. (1973). Loneliness: The experience of emotional and social isolation. Cambridge: MIT Press.

Wiggins, J. D., \& Lederer, D. A. (1984). Differential antecedents of infidelity in marriage. American Mental Health Counselors Association Journal, 6(4), 152-161. http://psycnet.apa.org/psycinfo/1985-22492001.

Whisman, M. A., Dixon, A. E., \& Jonhson, B. (1997). Thearapists' perspectives of couple problems and treatment issues in couple therapy. Journal of Family Psychology, 11, 361-366.

Yum, Y. O. (2003). The relationships among loneliness, self/partner constructive maintenance behavior, and relational satisfaction in two cultures. Communication Studies, 54, 451-467. doi:10.1080/1051097030 9363303. 